\title{
Kapadokya'yı Ziyaret Eden Yabancı Turistlerin Yiyeceklere Karşı Çeşitlilik Arayışlarının İncelenmesi
}

\author{
Investigation of Interactions of Difference From Foreign Tourists to Visit \\ Cappadocia
}

\author{
Dr. Öğr. Üyesi Seda DERINALP ÇANAKÇı \\ Kafkas Üniversitesi \\ Sarıkamış Turizm Fakültesi \\ E-posta: sedaderinalp@yahoo.com \\ Orcid Id: 0000-0001-6530-8813
}

\author{
Prof. Dr. Kemal BíRDiR \\ Mersin Üniversitesi \\ Turizm Fakültesi \\ Orcid Id: 0000-0003-1353-3618
}

E-posta: kemalbirdir@mersin.ed.tr

\section{Öz}

Bu çalışmanın amacı, Kapadokya'yı ziyaret eden yabancı turistlerin yiyeceklere karşı çeşitlilik arayışlarını belirlemek ve yabancı turistlerin çeşitlilik arayışı eğilimlerinin demografik özelliklerine göre farklılık gösterip göstermediğini ortaya koymaktır. Anket, Ağustos - Ekim 2015 tarihleri arasında, Kapadokya'yı ziyaret edip, Kayseri Erkilet Havalimanı'ndan ayrılan turistler üzerinde uygulanmıştır. Anketlerin uygulanmasında, bırak ve topla yöntemi kullanılmıştır. Araştırmaya katılan yabancı turistlerin yiyeceklere karşı çeşitlilik arayışlarının iki boyutta toplandığı tespit edilmiştir. Bunlar; "merak" ve "deneyim" boyutları olarak adlandırılmışlardır. Çeşitlilik arayışları boyutları ile "yaş grupları" arasında yapılan varyans analizi sonucu, "merak" ve "deneyim" boyutlarının turistlerin "yaş gruplarına" göre anlamlı farklılık gösterdiği belirlenmiştir. Ayrıca, "deneyim" boyutunun turistlerin "çalışma durumlarına" ve "eğitim durumlarına" göre de anlamlı farklııı gösterdiği ortaya çıkmıştır.

Anahtar Kelimeler: Çeşitlilik arayışı, gastronomi, gastronomi turizmi.

\section{Abstract}

The aim of this study is to determine the food variety seeking of foreign tourists who visit Cappadocia and to determine whether foreign tourists' diversity search tendencies differ according to their demographics. The survey was conducted on tourists who visited Cappadocia and left the region via Kayseri Erkilet Airport between August and October 2015. In the implementation of the questionnaires, drop and collect method was used. It has been found that the food variety seeking of foreign tourists participating in the research is gathered in two dimensions. These are named "Curiosity" and "experience" dimensions. It has been determined from the results of variance analysis between the dimensions of variety seeking and "age groups", the "curiosity" and "experience" dimensions show significant difference according to the "age groups" of tourists. Additionally, it has been found that the "experience" dimension shows significant difference according to "working" and "education" conditions of tourists.

Key Words: Variety seeking, gastronomy, gastronomy tourism. 


\section{Giriş}

Yeni lezzetler tatmak ve farklı kültürlere ait yiyecekleri deneyimlemek (Kim ve diğ., 2009; Quan ve Wang, 2004; Frochot, 2008; Cohen ve Avieli, 2004) bireylere kültürler arasındaki farklılıkları yaşama fırsatı vermektedir. Literatürde gastronomi turizmi olarak kavramsallaşan ve küreselleşen toplumlarda kültür kimliğinin önemli bir belirleyici unsuru olarak gösterilen bu durum, yiyecek aracılığı ile turistlere birden çok katkı sağlamaktadır (Winter ve diğ., 2008). Yerel ve özgün yiyecekleri deneyimleme ve motive olma (Kivela ve Crotts, 2006; Fotopoulos ve diğ., 2009; Kim ve diğ., 2009; Chang ve diğ., 2011; Kim ve diğ., 2010; Pearson ve diğ., 2011; Kesici, 2012; Kodaş, 2013; Bayrakçı, 2014; Akdağ ve diğ., 2015), yerel kültürü gözlemleme (Handszuh, 2000; Joliffe, 2003; Ignatov ve Smith, 2006; Kivela ve Crotts, 2009; Sims, 2009), etkinliklere katılım gösterme (Kivela ve Crotts, 2006; Smith ve Costello, 2009; Çağlı, 2012; Bekar ve Kılıç, 2014) ve memnuniyet (Hjalager ve Corigliano, 2000; Chang ve diğ., 2011) olarak sıralanan bu katkılar incelendiğinde gastronominin farklı yiyecekleri deneyimlemekten çok daha fazlasını kapsadığı görülmektedir. Diğer taraftan yiyecek ve turizm arasında güçlü bir ilişki olduğu (Boyne ve diğ., 2002) alan yazın ile desteklenmektedir. Söz gelimi, Yüksel (2001)'in Türkiye'de yaptığı çalışmasında; yiyecek, Türkiye'yi ilk defa ziyaret eden turistler ve tekrar Türkiye'yi tercih eden turistler açısından temel çekicilik unsuru olarak belirlenmiştir. Benzer şekilde Hall ve Sharples (2003) de yiyeceğin bir turist açısından temel ziyaret sebebi olabileceğini ortaya çıkarmışlardır. Enright ve Newton (2005)'un Hong Kong, Singapur ve Bongkok'u karşılaştırdıkları çalışmalarında yiyeceğin, Hong Kong'u tercih etme nedenleri arasında ikinci, Bangkok için dördüncü ve Singapur için ise beşinci sırada yer aldığı belirlenmiştir. Rimmington ve Yüksel (1998)'in Türkiye'de yaptıkları çalışmalarında yiyeceğin destinasyonu tercih nedenleri arasında dördüncü sırada olduğu belirlenmiştir. Üner ve diğ. (2006) İstanbul şehrinin yabancı ziyaretçiler gözündeki imajının değerlendirildiği çalışmalarında yiyeceğin beşinci önemli faktör olduğu tespitine varmışlardır.

Sözü edilen çalışmalar, turistlerin ziyaret ettikleri destinasyonlarda doğal, tarihi ve kültürel öğeleri ziyaret etmelerinin yanı sıra, yiyeceğe dayalı yenilikleri araştırmak ve çeşitli deneyimler elde etmek amacıyla seyahat ettiklerini göstermektedir (Au ve Law, 2002: 825; Guzman ve Canizares, 2011: 63). Bu bağlamda, gastronomiye dayalı çeşitlilik arayışı eğilimi gösteren turist sayısı gittikçe artış göstermektedir. Yapılan alan yazın taraması sonucu, Türkiye'yi ziyaret eden yabancı turistlere yönelik yiyeceklerde çeşitlilik arayışı eğiliminin araştırılmadığı belirlenmiştir. Bu çalışma, Kapadokya'yı ziyaret eden yabancı turistlerin yiyeceklere karşı çeşitlilik arayışlarını belirlemek amacını taşımaktadır. Ayrıca, yabancı turistlerin çeşitlilik arayışı eğilimlerinin demografik özelliklerine göre farklılık gösterip göstermediğine de yer verilmektedir.

\section{2. Çeşitlilik Arayışı Kavramı}

Çeşitlilik arayışı daha çok pazarlama bilim dalında incelenmiş bir konu olmakla birlikte (McAlister ve Pessemier, 1982; Menon ve Kahn, 1995; Kahn, 1995; Baumgartner ve Steenkamp, 1996; Van Trijp ve diğ., 1996; Legoherel, 1998; Ratner ve diğ., 1999; Berne ve diğ., 2001; Roehm ve Roehm, 2005; Enrique Bigne ve diğ., 2009; Nicolau, 2010; Punj, 2011; Desai ve Trivedi, 2014) genel eğilimi, bir ürünün özelliklerine doyma, daha önce denenmemiş veya bilinmeyene yönelik bir yenilik arayışı (McAlister ve Pessemier, 1982: 315), gelecekteki belirsizlikleri aşma isteği (Kahn, 1995: 140) olarak tanımlanmaktadır. Meixner ve Knoll (2012: 1573)'a göre, tüketiciler bir üründen tam doygunluk sağladığında dahi monotonluğu gidermek adına ürün markasını değiştirme eğilimine girmektedirler. Bu tür davranış değişiklikleri tatmin edici düzeyde uyarılma 
oluşturarak sıkıntı ve bıkkınlığı gidermektedir. Çeşitlilik arayışı eğilimine yönelik yapılan bu tanımı destekler nitelikte Menon ve Kahn (1995: 285), farklı veya yeni bir ürüne geçiş yapmanın satın alma durumundaki uyarılmayı arttırdığını vurgulamaktadır. Buna göre, bir kişinin gerçek uyarılma düzeyi optimum uyarılma düzeyi altına indiğinde kişide uyarılma düzeyi arayışı başlamaktadır. Uyarılma düzeyi optimum düzeyin üzerine çıktığında ise, kaçınma davranışları başlamaktadır. Optimum uyarılma düzeyi, tüketicilerin çeşitlilik arayışı davranışlarında oldukça sık kullanılan bir teoridir (Steenkamp ve Baumgarter, 1992; Inman, 2001; Orth ve Bourrain, 2005; Jangand Feng, 2007). Steenkamp ve Baumgartner (1992), yiyecek tüketimi konusunda çeşitlilik arayışı ve optimum uyarılma düzeyi arasında dikkate değer bir bağlantı bulunduğunu belirtmişlerdir (Meixner ve Knoll, 2012: 1573).

Çeşitlilik arayışı, turizm alanında (Hu ve diğ., 2002; Jang ve Feng, 2007; Enrique Bigne ve diğ., 2009; Beldona ve diğ., 2010; Legoherel ve diğ., 2012) ve yiyecek sektöründe de (Van Trijp ve Steenkamp, 1992; Kwun ve Oh, 2004; Shenoy, 2005; Jung ve Yoon, 2012; Ha ve Jang, 2013) incelenmiş bir konudur. Konu ile alakalı olarak yiyeceklerde çeşitlilik arayışı, turistlerin yiyecek tüketimini etkileyen bireysel bir eğilim olarak karşımıza çıkmaktadır. İnsanların mal ve hizmet tercihlerinde çeşitlilik/farklılık arama eğilimi, farklı mutfak gelenekleri ve/veya mutfak sistem çeşitliliği talebini açıklayan bir kavramdır. Bir başka ifade ile yiyeceklerde çeşitlilik arayışı, alışık olunmayan yiyecekleri denemekten hoşlanma, yemek hazırlarken yeni tarifler deneme, farklı ülkelerdeki yemekleri merak etme, egzotik yiyecekleri deneyimleme şeklinde ortaya çıkmaktadır (Kahn, 1995: 139-148; Germann, 2004: 53-75). Lezzet gibi duyusal özelliklerin marka gibi duyusal olmayan özelliklere göre daha fazla deneyimlenme isteği (Inman, 2001: 105-120) turistlerin hazcı (hedonik) tüketim durumlarında sıklıkla ortaya çıkmaktadır. Hedonik ürünlerin tüketiciye eğlence, memnuniyet gibi duygusal anlamda faydası göz önüne alındığında gastronomi turizmi de hedonik bir ürün olarak kabul edilmekte ve çeşitlilik arayışı aracılığı ile turistik ürünler de bundan etkilenmektedir (Mak ve diğ., 2012: 932-934).

Ulusal ve uluslararası alan yazında yapılan kapsamlı bir tarama sonucunda, yiyeceklerde çeşitlilik arayışına yönelik yapıımış yalnızca uluslararası çalışmaların var olduğu ortaya çıkmıştır. Bu çalışmalardan bazıları aşağıda sunulmuştur.

Örneğin Shenoy (2005), Amerika'nın Güney Karolina eyaletini ziyaret eden yabancı turistlerin gastronomi turizmi kapsamında genel yiyecek tercihleri ve yiyeceklere karşı çeşitlilik arayışlarını incelemiştir. Çalışma sonunda, yerel alışveriş, yöresel akşam yemeği, yerel içecek, lüks yemek ve aşinalık olarak ortaya çıkan genel yiyecek tercihlerinden yöresel akşam yemeği, yerel içecek ve yerel alışveriş faktörlerinin çeşitlilik arayışı eğilimi üzerinde anlamlı etkiye sahip olduğu ortaya çıkmıştır.

Beldona ve diğ. (2010), Hindistan'ın Banglore şehrinde iki farklı restoranda öğle ve akşam yemeği yiyen tüketiciler üzerinde ilgilenim ve çeşitlilik arayışı faktörlerinin rolünü incelemişlerdir. Tüketicilerin az/çok çeşitlilik arayışında olanlar ile az/çok ilgilenimli olanlar olarak gruplandığı araştırma sonucuna göre, diğer gruplara kıyasla ilgilenim ve çeşitlilik arayışı çok olan tüketicilerin dışarıda yemek yeme davranışlarının daha yüksek olduğu ortaya çıkmıştır.

Legoherel ve diğ. (2012), Hong Kong'ta turistlerin yiyecek ile ilgili ürünleri satın alma davranışlarında keşif ve çeşitlilik arayışı eğilimlerini incelenmişlerdir. Araştırma, turistlerin yeni lezzetler deneyimlemeye karşı olan keşif ve çeşitlilik arayışı eğilimleri üzerine restoran tercihi yapmakta olduklarını ortaya çıkarırken, turistlerin kültürel 
özelliklerinin satın alma davranışlarında çeşitlilik arayışı eğilimlerine önemli etkisi olduğunu ortaya çıkarmıştır. Çok çeşitlilik arayışında olan turistlerin ise sadık oldukları ürünlerden çabuk vazgeçebilme eğilimde olduğu araştırmanın ortaya çıkardığı bir diğer sonuçtur.

Kwun ve diğ. (2013), Güney Kore'de tüketicilerin dışarıda yemek yeme motivasyonları ve çeşitlilik arayışı davranışlarının tüketici sadakati üzerindeki etkisini incelemişlerdir. Dışarıda yemek yeme motivasyonlarının tüketici sadakati üzerinde çok/az çeşitlilik arayışında olan tüketiciler arasında farklılıklara rastlanılmıştır. Çok çeşitlilik arayışında olan tüketiciler açısından, hazcı değer, sağlıklı yaşam ve promosyona dayalı faktörler müşteri sadakati konusunda ön plana çıkarken, az çeşitlilik arayışında olan tüketiciler açısından, hazcı değer ve atmosfer faktörleri müşteri sadakati konusunda ön plana çıkmaktadır.

Baltas ve diğ. (2011), tüketicilerin lezzete yönelik hazcı çeşitlilik arayışı ile kokuya yönelik faydacı çeşitlilik arayışı derecelerinin karşılaştırılması üzerine bir araştırma gerçekleştirmişlerdir. Araştırma, lezzete yönelik hazcı faktörlerin kokuya yönelik hazcı faktörlere oranla daha önemli olduğu, kokuya yönelik faydacı faktörlerin lezzete yönelik faydacı faktörlere oranla daha önemli olduğu sonucunu ortaya çıkarmıştır. Diğer taraftan tüketicilerin lezzete yönelik hazcı çeşitlilik arayışları, kokuya yönelik faydacı çeşitlilik arayışlarından daha yüksektir.

\section{Araştırmanın Amacı ve Yöntemi}

Bu araştırma, Kapadokya'yı ziyaret eden yabancı turistlerin yiyeceklere karşı çeşitlilik arayışlarını belirlemek ve yabancı turistlerin çeşitlilik arayışı eğilimlerinin demografik özelliklerine göre farklıık gösterip göstermediğini ortaya koymak amacı ile yapılmıştır.

Yabancı turistlerin yiyeceklere karşı çeşitlilik arayışlarını belirlemek için, araştırma alanı olarak Kapadokya bölgesi seçilmiştir. Yabancı turistlerin özellikle kültür amaçlı ziyaret ettiği Kapadokya bölgesi; yiyecek üretim tesisleri, şarap tadım merkezleri, bağ bozumu festivali, çiftçi pazarları, üzüm bağları ve restoranlar gibi arz ürünleri ile gastronomi turizmine yönelik önemli bir çekim yeri niteliği taşımaktadır.

Araştırma verilerinin toplanmasında anket kullanılmıştır. İngilizce dilinde hazırlanan ankette yer alan sorular, iki bölümden oluşmaktadır. Birinci bölümde, turistlerin demografik ve seyahat özelliklerine ilişkin sorular yer almaktadır. İkinci bölümde, Van Trijp ve Steenkamp (1992) tarafından geliştirilen, yabancı turistlerin yiyeceklere karşı çeşitlilik arayışı eğilimlerini belirlemeye yönelik sorular bulunmaktadır. Söz konusu ölçek sekiz maddeden oluşmaktadır. Bu doğrultuda turistlerin her bir özelliğe ilişkin katıım düzeyleri "kesinlikle katılmıyorum" (1), "katılmıyorum" (2), "emin değilim" (3), "katılıyorum" (4), "kesinlikle katılıyorum" (5) seçeneklerinden birini seçerek belirtmeleri istenmiştir. Ölçekte yer alan 7. madde; "Alışık olduğum yiyecekleri yemeği tercih ederim" ifadesi ters kodlanmıştır.

Ankette yer alan soruların anlaşılır olup olmadığının tespit edilmesi amacı ile 0615 Temmuz 2015 tarihleri arasında Kapadokya'yı ziyaret eden ve Kayseri Erkilet Havalimanı'ndan ayrılan 135 yabancı turist üzerinde ön test yapılmıştır. Sekiz maddelik çeşitlilik arayışı ölçeğinin Cronbach's Alpha katsayısı 0,737 olarak ortaya çıkmıştır.

Araştırma örneklemine girecek yabancı turistler, kolayda örnekleme yöntemiyle seçilmiştir. Kolay uygulanabilen, ucuz ve zaman alıcı olmayan bu yöntem ile anket 2015 yılı Ağustos-Ekim ayları arasında uygulanmıştır. Anketin uygulanma sürecinde, 
yabancı turistler ile yüz yüze temas kurularak anketler dağıtıImıştır. Uygulama sonucu 521 adet kullanılabilir anket elde edilmiştir. Verilerin analizinde tanımlayıcı istatistiklerin yanı sıra, t-testi, varyans ve faktör analizlerinden yararlanılmıştır.

Veri analiz sürecinde ölçeğe normal dağılım testi ve sapan analizi uygulanmıştır. $\mathrm{Bu}$ testler verilerin açıklayıcı faktör analizine uygun olup olmadığını belirlemek amacıyla yapılmıştır. Verilerin normal dağılıma uygunluğunun incelenmesi için çarpıklık (skewness) ve basıklık (kurtosis) testlerinden yararlanılmıştır. Ölçeğin çarpıklık ve basıklık değerlerinin \pm 3 aralığında yer aldığı tespit edilmiş ve normallik açısından uygun dağılım gösterdiği belirlenmiştir. Ölçeğin güvenirliği hesaplanmış ve Cronbach's Alpha değerinin oldukça güvenilir $(0,818)$ olduğu görülmüştür.

\section{Bulgular ve Değerlendirme}

Tablo 1, araştırmaya katılan yabancı turistlerin demografik özellikleri hakkında bilgi vermektedir. Buna göre, araştırmaya katılan turistlerin \%58,7'sinin "kadın" ve \%41,3'ünün "erkek" olduğu belirlenmiştir. Turistlerin çoğunlukla "25-35" yaş aralığında (\%31,7), "evli" (\%54,9), "lisans" mezunu (\%45,3), "özel sektörde çalışan" $(\% 43,6)$ ve "orta" gelir düzeyinde $(\% 56,8)$ kişiler olduğu belirlenmiştir. Araştırmaya katılan yabancı turistlerin milliyetleri incelendiğinde \%16,1'inin "Amerikalı", \%7,1'inin "Alman", $\% 6,7$ 'sinin "Avustralyalı", \%5'inin "Kanadalı", \%4,8'inin "İngiliz" ve \%60,3'ünün ise diğer milliyetlerden olduğu anlaşılmaktadır

Tablo 1: Katılımcıların Demografik Özelliklerinin Dağılımı

\begin{tabular}{|c|c|c|c|c|c|}
\hline & $\mathbf{F}$ & $\%$ & & $\mathbf{F}$ & $\%$ \\
\hline Cinsiyetiniz & & & Yaşınız & & \\
\hline Kadın & 306 & 58,7 & $15-24$ yaş arası & 37 & 7,1 \\
\hline Erkek & 215 & 41,3 & $25-35$ yaş arası & 165 & 31,7 \\
\hline Toplam & 521 & 100,0 & $36-46$ yaş arası & 99 & 19,0 \\
\hline Milliyetiniz (en çok 5) & & & $47-60$ yaş arası & 127 & 24,4 \\
\hline Amerikalı & 84 & 16,1 & 61 ve üstü & 93 & 17,9 \\
\hline Alman & 37 & 7,1 & Toplam & 521 & 100,0 \\
\hline Avustralyalı & 35 & 6,7 & Eğitim Durumu & & \\
\hline Kanadalı & 26 & 5,0 & İlkokul & 3 & 0,6 \\
\hline İngiliz & 25 & 4,8 & Ortaokul & 13 & 2,5 \\
\hline Diğer & 314 & 60,3 & Lise & 75 & 14,4 \\
\hline Toplam & 521 & 100,0 & Lisans & 236 & 45,3 \\
\hline Medeni Durum & & & Lisansüstü & 194 & 37,2 \\
\hline Evli & 286 & 54,9 & Toplam & 521 & 100,0 \\
\hline Dul & 16 & 3,1 & Meslek & & \\
\hline Boşanmış veya ayrı & 33 & 6,3 & Özel sektörde çalışan & 227 & 43,6 \\
\hline Hiç evlenmemiş & 116 & 22,3 & Kamu çalışanı & 63 & 12,1 \\
\hline Sevgili & 70 & 13,4 & İş yeri sahibi & 90 & 17,3 \\
\hline Toplam & 521 & 100,0 & Öğrenci & 27 & 5,2 \\
\hline Gelir Düzeyi & & & Emekli & 81 & 15,5 \\
\hline Çok düşük & 3 & 0,6 & Ev hanımı & 14 & 2,7 \\
\hline Düşük & 26 & 5,0 & İşsiz & 7 & 1,3 \\
\hline Orta & 296 & 56,8 & Diğer & 12 & 2,3 \\
\hline Yüksek & 179 & 34,4 & Toplam & 521 & 100,0 \\
\hline Çok yüksek & 17 & 3,3 & & & \\
\hline Toplam & 521 & 100,0 & & & \\
\hline
\end{tabular}


Tablo 2, araştırmaya katılan yabancı turistlerin seyahat özellikleri hakkında bilgi vermektedir. Buna göre katılımcıların \%70,4'ü seyahatlerini "bireysel" olarak organize ederken \%29,6'sı "paket tur" ile organize etmektedirler. Katılımcıların \%68,5'i Türkiye'yi daha önce ziyaret etmemişlerdir. Türkiye'yi daha önce ziyaret edenler çoğunlukla $(\% 24,4)$ "1-3 arası" ziyaret etmişlerdir. Diğer taraftan araştırmaya katılan yabancı turistlerin Türkiye'deki seyahatlerinin toplam süreleri ise çoğunlukla $(\% 55,9)$ "6-10 gün arası"dır.

Tablo 2: Katılımcıların Seyahat Özelliklerinin Dağılımı

\begin{tabular}{|c|c|c|c|c|c|}
\hline & $\mathbf{F}$ & $\%$ & & $\mathbf{F}$ & $\%$ \\
\hline $\begin{array}{l}\text { Seyahatinizi nasıl } \\
\text { organize ettiniz? }\end{array}$ & & & $\begin{array}{l}\text { Türkiye'yi daha önce } \\
\text { ziyaret ettiniz mi? }\end{array}$ & & \\
\hline Bireysel & 367 & 70,4 & Evet & 164 & 31,5 \\
\hline Paket Tur & 154 & 29,6 & Hayır & 357 & 68,5 \\
\hline Toplam & 521 & 100,0 & Toplam & 521 & 100,0 \\
\hline $\begin{array}{l}\text { Türkiye'ye daha } \\
\text { önce kaç kez geldiniz? }\end{array}$ & & & $\begin{array}{l}\text { Türkiye'deki } \\
\text { seyahatinizin } \\
\text { toplam süresi kaç } \\
\text { gündür? }\end{array}$ & & \\
\hline $1-3$ arası & 127 & 24,4 & $1-5$ gün arası & 82 & 15,7 \\
\hline 4-7 arası & 21 & 4,0 & 6-10 gün arası & 291 & 55,9 \\
\hline 8 ve üstü & 16 & 3,1 & 10 günden fazla & 148 & 28,4 \\
\hline Toplam & 164 & 31,5 & Toplam & 521 & 100,0 \\
\hline
\end{tabular}

Kapadokya'yı ziyaret eden yabancı turistlerin yiyeceğe karşı çeşitlilik arayışlarını değerlendirmek amacıyla kullanılan çeşitlilik arayışı ölçeği sekiz maddeden oluşmaktadır. Ölçeğin madde bütün korelasyon katsayıları incelendiğinde tüm ifadelerin 0,25'ten büyük olduğu (Kalaycı, 2009: 412) ortaya çıkmıştır. Bu nedenle yapılan faktör analizine sekiz ifadenin tümü alınmıştır. Sekiz ifadelik ölçeğe uygulanan faktör analizi, ölçeği iki faktör altında toplamış ve toplam varyansın \%58,248'ini açıklamaktadır. Analiz neticesinde Kaiser-Mayer-Olkin (KMO) örneklem yeterliliği 0,847 olarak ortaya çıkmıştır. Barlett küresellik testi sonucuna göre elde edilen ki-kare değerinin 1264,924 ile 0,001 düzeyinde anlamlı olduğu ortaya çıkmıştır. Bu durum faktör analizine devam etme açısından sakınca olmadığını ortaya koymaktadır (Nakip, 2006: 430-431). Çeşitlilik arayışı ölçeğinin sekiz maddeden oluşması faktörlerin belirlenmesinde özdeğer yaklaşımının dışında diğer bir yaklaşım olan yamaç grafiği yaklaşımını da göz önünde bulundurmamız gerekliliğini ortaya koymuştur. En çok kullanılan yaklaşımlardan biri olan özdeğer yaklaşımının genellikle 20 ile 50 değişken olduğu durumlarda kullanılması önerilmektedir. Yamaç grafiği yaklaşımında ise grafikte eğimin azaldığı veya aynı kaldığı noktadaki özdeğer sayısı kadar faktörün dikkate alınması önerilmektedir (Alpar, 2011: 288).

Grafik 1 incelendiğinde faktör 2'den sonra eğimin çok azalan değerlere ulaştığı görülmektedir. Bu nedenle, önemli faktör sayısının iki olabileceği söylenebilir. Grafik, özdeğer yaklaşımı ile yamaç grafiği yaklaşımının farklı olmadığı sonucuna ulaşmamızı sağlamıştır. 


\section{Grafik 1: Faktör Analizinde Yamaç Grafiği Yaklaşımı}

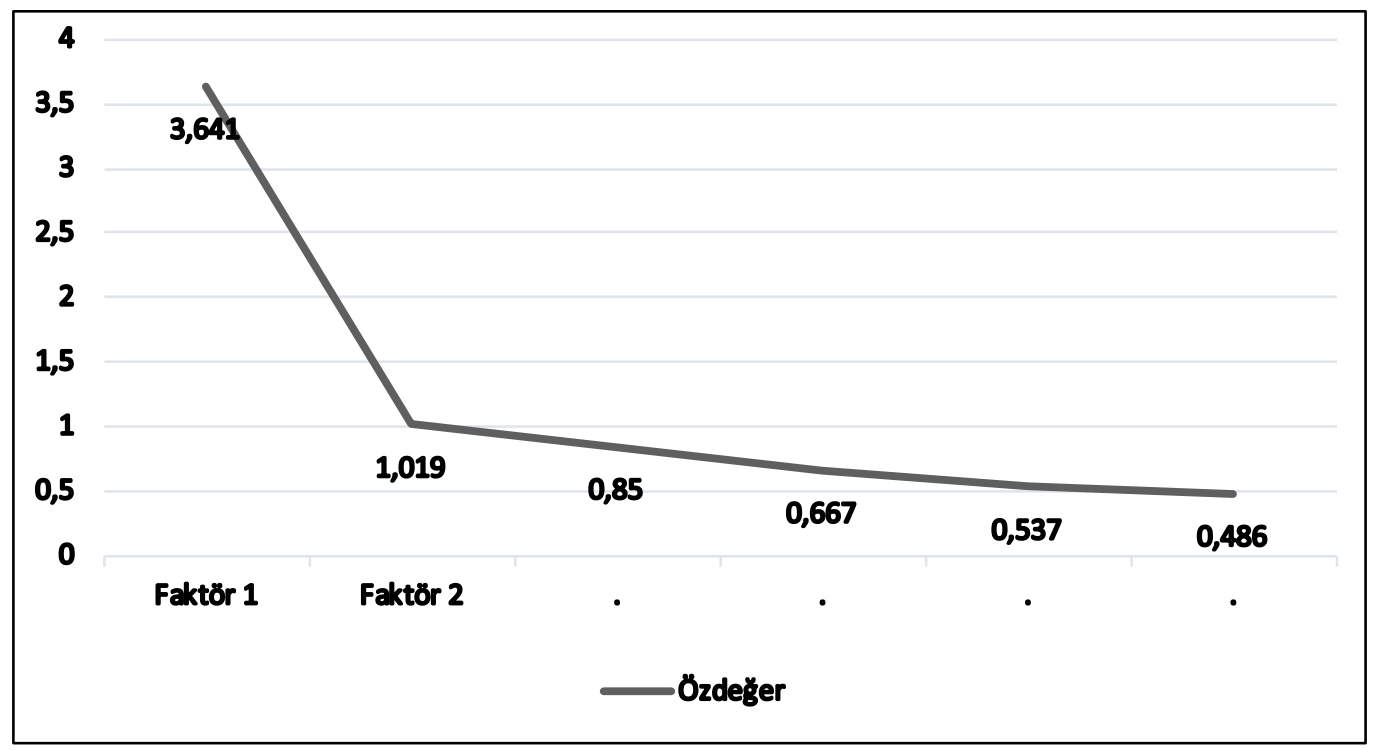

Tablo 3, çeşitlilik arayışı ölçeğine yapılan faktör analizi sonuçlarını göstermektedir. Yapılan faktör analizi, Kapadokya'yı ziyaret eden yabancı turistlerin yiyeceklerde çeşitlilik arayışlarının iki başlıkta incelenebileceğini göstermektedir.

Tablo 3: Çeşitlilik Arayışına İlişkin Faktör Analizi Sonuçları

\begin{tabular}{|c|c|c|c|c|c|c|}
\hline ÇEŞITLILIKK ARAYIŞI & 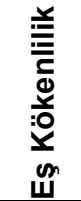 & 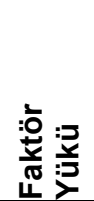 & 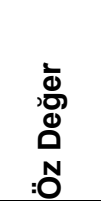 & 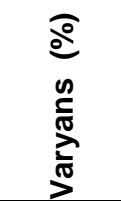 & $\begin{array}{l}\frac{\mathbb{2}}{\mathbb{E}} \\
\frac{\mathbb{N}}{\mathbb{T}} \\
\frac{\mathbb{t}}{0}\end{array}$ & 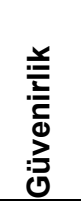 \\
\hline 1.MERAK (4 Madde) & & & 3,641 & 45,511 & 3,949 & ,793 \\
\hline $\begin{array}{l}\text { Menüde, alışık olmadığım yiyecekleri görmek, } \\
\text { bende merak uyandırır }\end{array}$ & ,741 & ,844 & & & & \\
\hline $\begin{array}{l}\text { Bana tanıdık gelmeyen yiyeceklere karşı } \\
\text { meraklıyımdır }\end{array}$ & 606 & ,758 & & & & \\
\hline $\begin{array}{l}\text { Farklı ülkelerde insanların ne çeşit yiyecekler } \\
\text { yediklerini bilmeye istekliyim }\end{array}$ & 541 & ,711 & & & & \\
\hline Egzotik yiyeceklerden hoşlanııı & ,591 & 675 & & & & \\
\hline 2.DENEYIM (4 Madde) & & & 1,019 & 12,737 & 3,675 & ,692 \\
\hline Alışık olduğum yiyecekleri yemeği tercih ederim & 598 & ,767 & & & & \\
\hline $\begin{array}{l}\text { Dışarıda yemek yediğimde, beğeneceğimden } \\
\text { emin olmasam da en sıra dışı yiyecekleri } \\
\text { denemekten hoşlanırım }\end{array}$ & ,621 & ,752 & & & & \\
\hline $\begin{array}{l}\text { Yemek veya aperitif hazırlarken, farklı reçeteler } \\
\text { denemekten hoşlanırım }\end{array}$ & ,402 & ,604 & & & & \\
\hline $\begin{array}{l}\text { Alışkın olmadığım yiyecekleri } \\
\text { eğlenceli olduğunu düşünüyorum }\end{array}$ &, 560 & ,597 & & & & \\
\hline
\end{tabular}


Tablo 3'ün Devamı

Varimax Rotasyonlu Temel Bileşenler Analizi - Açıklanan Toplam Varyans: \% 58,248 KMO Örneklem Yeterliliği: ,847 - Bartlett Küresellik Testi: $x^{2}$ : 1264,924 s.d.: 28 p<0.001 Genel Ortalama: 3,812 - Ölçeğin Tamamı için Alfa: ,818

Yanıt kategorileri: (1) Kesinlikle Katılmıyorum (2) Katılmıyorum (3) Emin Değilim

(4) Katılıyorum (5) Kesinlikle Katılıyorum

Elde edilen birinci faktör dört maddeden oluşmakta ve toplam varyansın \%45,511'ini açıklamaktadır. Faktörü oluşturan ifadeler ve faktör yükleri incelendiğinde "Menüde, alışık olmadığım yiyecekleri görmek, bende merak uyandırır (,844)", "Bana tanıdık gelmeyen yiyeceklere karşı meraklıyımdır $(, 758)$ ", "Farklı ülkelerde insanların ne çeşit yiyecekler yediklerini bilmeye istekliyim $(, 711)$ " ve "Egzotik yiyeceklerden hoşlanırım $(, 675)$ " şeklinde ifadelerin olduğu görülmektedir. Faktörde yer alan ifadeler daha çok yabancı yiyeceklerin tüketimine yönelik merak ve isteğe ilişkin ifadeler olduğundan birinci faktör "merak" olarak adlandırılmıştır.

Elde edilen ikinci faktör de dört maddeden oluşmakta ve toplam varyansın \%12,737'sini açıklamaktadır. Faktörü oluşturan ifadeler ve faktör yükleri incelendiğinde "Alışık olduğum yiyecekleri yemeği tercih ederim $(, 767)$ ", "Dışarıda yemek yediğimde, beğeneceğimden emin olmasam da en sıra dışı yiyecekleri denemekten hoşlanırım $(, 752)$ ", "Yemek veya aperitif hazırlarken, farklı reçeteler denemekten hoşlanırım $(, 604)$ " ve "Alışkın olmadığım yiyecekleri denemenin eğlenceli olduğunu düşünüyorum $(, 597)$ " şeklinde ifadelerin olduğu görülmektedir. Faktörde yer alan ifadelerin daha çok farklı yiyeceklerin deneyimlenme isteğine ilişkin ifadeler olmasından dolayı ikinci faktör "deneyim" olarak adlandırılmıştır.

Tablo 4, araştırmaya katılan turistlerin, yiyeceklere karşı çeşitlilik arayışları ile çalışma durumlarına yönelik varyans analizi sonucunu göstermektedir. Analiz sonucuna göre "deneyim" arayışı çalışma durumu değişkenine göre anlamlı farklılık göstermektedir. Buna göre "emekli" katılımcıların deneyim arayışı ortalamalarının "kamu çalışanı" ve "özel sektörde çalışan" katılımcılardan düşük olduğu ortaya çıkmıştır. Sonuçlar emekli turistlerin çeşitlilik arayışının düşük olduğuna işaret etmektedir. Bu durum yaşla beraber çeşitli sağlık sorunları da yaşamaya başlayan bireylerin çeşitliliğe mesafeli yaklaştığı şeklinde yorumlanabilir.

Tablo 4: Çalışma Durumu Değişkenine Göre Çeşitlilik Arayışına Uygulanan ANOVA Analizi

\begin{tabular}{|c|c|c|c|c|c|c|c|}
\hline Çeşitlilik Arayışı & \multicolumn{2}{|c|}{ Çalışma Durumu } & $\mathbf{n}$ & Ort. & $\begin{array}{l}\text { Std. } \\
\text { Sapma }\end{array}$ & F Değeri & Farklılık \\
\hline \multirow{8}{*}{ Deneyim } & A & $\begin{array}{l}\text { Özel sektörde } \\
\text { calışan }\end{array}$ & 227 & 3,7752 & 63739 & \multirow{8}{*}{3,317} & \multirow{8}{*}{$\begin{array}{l}E<B \text { ve } \\
A\end{array}$} \\
\hline & $B$ & Kamu çalışanı & 63 & 3,8413 & ,65884 & & \\
\hline & C & İş yeri sahibi & 90 & 3,5359 & ,65004 & & \\
\hline & $\mathrm{D}$ & Öğrenci & 27 & 3,6389 &, 51578 & & \\
\hline & $E$ & Emekli & 81 & 3,5240 & ,65985 & & \\
\hline & $\mathrm{F}$ & Ev hanımı & 14 & 3,5714 & .76854 & & \\
\hline & $\mathrm{G}$ & İsssiz & 7 & 3,3571 & ,53730 & & \\
\hline & $\mathrm{H}$ & Diğer & 12 & 3,3750 & 63514 & & \\
\hline
\end{tabular}

Çeşitlilik arayışı ile yabancı turistlerin yaş gruplarına yönelik yapılan varyans analizi sonucunda (Tablo 5) her iki boyutta da anlamlı farklılıklara rastlanılmıştır. Söz konusu her iki ifadeye "15-24" yaş grubundaki katılımcıların diğer yaş gruplarına oranla 
daha az katıldıkları görülmektedir. Buna göre ortalamalar arasındaki en büyük farkın "15-24" yaş grubundaki katılımcılar ile "25-35" yaş grubu ve "36-46" yaş grubundaki katılımcılar arasında gerçekleştiği görülmektedir. Sonuçlar genç grupların da çeşitliliğe mesafeli yaklaştığını göstermektedir. Pizza, hamburger gibi küreselleşmiş bazı tatların gençlerin yiyecek tercihlerini güçlü bir şekilde etkilediği düşünüldüğünde, sonuçların anlamlı olduğu ileri sürülebilir.

Tablo 5: Yaş Grupları Değişkenine Göre Çeşitlilik Arayışına Uygulana ANOVA Analizi

\begin{tabular}{|c|c|c|c|c|c|c|c|}
\hline Çeşitlilik Arayışı & \multicolumn{2}{|c|}{ Yaş Grubu } & \multirow{2}{*}{$\begin{array}{l}\mathbf{n} \\
37\end{array}$} & \multirow{2}{*}{$\begin{array}{l}\text { Ort. } \\
3,7297\end{array}$} & \multirow{2}{*}{$\begin{array}{l}\begin{array}{l}\text { Std. } \\
\text { Sapma }\end{array} \\
68308\end{array}$} & F Değeri & Farklılık \\
\hline \multirow{5}{*}{ Merak } & A & $\begin{array}{l}15-24 \quad \text { yaş } \\
\text { arası }\end{array}$ & & & & \multirow{5}{*}{3,740} & \multirow{5}{*}{$A<B$ ve $C$} \\
\hline & B & $\begin{array}{l}25-35 \text { yaş } \\
\text { arası }\end{array}$ & 165 & 4,0892 & ,59582 & & \\
\hline & C & $\begin{array}{l}36-46 \quad \text { yaş } \\
\text { arası }\end{array}$ & 99 & 3,9249 & ,63619 & & \\
\hline & D & $\begin{array}{l}47-60 \quad \text { yaş } \\
\text { arası }\end{array}$ & 127 & 3,8917 & ,64346 & & \\
\hline & $E$ & $\begin{array}{l}61 \text { yaş ve } \\
\text { üstü }\end{array}$ & 93 & 3,8918 & 60154 & & \\
\hline \multirow{5}{*}{ Deneyim } & A & $\begin{array}{l}15-24 \quad \text { yaş } \\
\text { arası }\end{array}$ & 37 & 3,4865 & ,60365 & \multirow{5}{*}{2,522} & \multirow{5}{*}{$A<B$ ve $C$} \\
\hline & B & $\begin{array}{l}25-35 \text { yaş } \\
\text { arası }\end{array}$ & 165 & 3,7788 & ,63642 & & \\
\hline & C & $\begin{array}{l}36-46 \quad \text { yaş } \\
\text { arası }\end{array}$ & 99 & 3,7195 & ,64330 & & \\
\hline & D & $\begin{array}{l}47-60 \text { yaş } \\
\text { arası }\end{array}$ & 127 & 3,6004 & ,65938 & & \\
\hline & $E$ & $\begin{array}{l}61 \text { yaş ve } \\
\text { üstü }\end{array}$ & 93 & 3,6228 & ,67876 & & \\
\hline
\end{tabular}

${ }^{\star}: p<, 05 ;{ }^{* \star} p<, 01 ;{ }^{* \star \star} p<, 001$

Tablo 6, araştırmaya katılan turistlerin yiyeceklere karşı çeşitlilik arayışları ile eğitim durumlarına yönelik varyans analizi sonucunu göstermektedir. Yapılan analiz sonucunda anlamlı farklılık bulunan çeşitlilik arayışı boyutu "deneyim" olarak belirlenmiştir. Sonuçlar, "ilkokul" mezunu katılımcıların çeşitlilik arayışı ifadesine diğer katılımcılara oranla daha az önem verdiklerini göstermektedir. Eğitim düzeyi arttıkça, yiyecekte çeşitlilik arayışının arttığı ileri sürülebilir.

Tablo 6: Eğitim Durumu Değişkenine Göre Çeşitlilik Arayışına Uygulanan ANOVA Analizi

\begin{tabular}{|l|l|l|l|l|l|l|l|}
\hline Çeşitlilik Arayışı & \multicolumn{2}{|l|}{ Eğitim Durumu } & $\mathbf{n}$ & Ort. & $\begin{array}{l}\text { Std. } \\
\text { Sapma }\end{array}$ & \multirow{2}{*}{ F Değeri } & Farklılık \\
\hline \multirow{5}{*}{ Deneyim } & A & Illkokul & 3 & 3,5000 &, 43301 & & \\
\cline { 2 - 6 } & B & Ortaokul & 13 & 3,7115 &, 48783 & \multirow{3}{*}{2,412} & \multirow{3}{*}{ A< D ve B } \\
\cline { 2 - 6 } & C & Lise & 75 & 3,5933 &, 63509 & \\
\cline { 2 - 5 } & D & Lisans & 236 & 3,7700 &, 62054 & & \\
\cline { 2 - 5 } & E & Lisansüstü & 194 & 3,5924 &, 69745 & & \\
\hline
\end{tabular}

${ }^{\star}: \mathrm{p}<, 05 ;{ }^{* \star} \mathrm{p}<, 01 ;{ }^{* \star *} \mathrm{p}<, 001$ 
Öte yandan, çeşitlilik arayışı ile "cinsiyet", "medeni durum" ve "gelir düzeyi"ne yönelik t-testi ve varyans analizi uygulanmış ancak çeşitlilik arayışı ile sözü edilen değişkenler arasında anlamlı farklılıklara rastlanılmamıştır.

\section{Sonuç}

Bu çalışma, Kapadokya'yı ziyaret eden yabancı turistlerin yiyeceklere karşı çeşitlilik arayışlarını belirlemeye yönelik olup, çeşitlilik arayışlarının demografik özelliklerine göre farklılık gösterip göstermediğini belirlemeye çalışmıştır.

Kapadokya'yı ziyaret eden yabancı turistlerin yiyeceğe karşı çeşitlilik arayışları incelendiğinde, yiyeceklere merak güdüsüyle yaklaştıkları ve deneyim arayışında oldukları belirlenmiştir. Alışık olunmayan yiyecekleri denemekten hoşlanma, yemek hazırlarken yeni tarifler deneme, farklı ülkelerdeki yemekleri merak etme, egzotik yiyecekleri deneyimleme şeklinde ortaya çıkan çeşitlilik arayışında (Kahn, 1995: 139148; Germann, 2004: 53-75) merak, Kim ve diğ. (2009)'ne göre psikolojik sebeplerden dolayı ortaya çıkmaktadır. Yazarlara göre, özellikle yerel yiyecek tüketim sebepleri bireylerin çeşitlilik arayışındaki merak güdülerini etkilemektedir. Diğer taraftan Redl (2013), çalışmasında turistlerin farklı deneyim elde etmek, yerel yiyecek kültürünü keşfetmek amacıyla tatillerinde sıklıkla yeni yiyecekleri test ettiklerini ve aktivitelere katılım gösterdiklerini bulgulamıştır. Yazar, çalışmasında turistlerin bu tip etkinliklere ve yiyeceklere ilgi göstermelerinin farklı deneyim elde etme üzerinde önemli etkisi olduğunu vurgulamıştır.

Yabancı turistlerin yiyeceklere karşı çeşitlilik arayışlarının demografik özelliklerine göre farklılık gösterip göstermediğinin belirlenmesi amacıyla yapılan t-testi ve varyans analizleri sonucunda "cinsiyet", "medeni durum" ve "gelir düzeyine" göre anlamlı farklılıklara rastlanılmamıştır. Bununla birlikte, çeşitlilik arayışları ile "çalışma durumuna" göre yapılan analiz sonucunda anlamlı farklılıklara rastlanılmış ve "emekli"lerin kamu ve özel sektör çalışanlarına göre "deneyim" faktörüne daha düşük ortalamalarla katıldıkları belirlenmiştir. Emeklilerin yaşlanmayla beraber yaşamaya başladıkları sağlık sorunlarının, yiyeceklerde yeni deneyimlere daha temkinli davranmalarına yol açtığı ileri sürülebilir.

Çeşitlilik arayışı ile "yaş gruplarına" yönelik yapılan varyans analizi sonucu "2535" yaş grubu katılımcılar ile diğer yaş grubundaki katılımcılar arasında söz konusu "merak" ve "deneyim" arayışlarında anlamlı farklılıklar gözlemlenmiştir. Buna göre "2535" yaş grubundaki katılımcılar çeşitlilik arayışına dair belirlenen her iki faktöre de daha fazla önem atfetmektedirler. Araştırma sonucunu destekler nitelikte Rızaoğlu ve diğ. (2014) de farklı yaşlardaki yabancı turistlerin yiyeceğe karşı eğilimlerinin değiştiğini ortaya koymuşlardır. Yiyeceklerde çeşitlilik arayışı eğilimi 56 yaş ve üzeri yaş grubuna kadar yükseliş göstermekte, ancak 56 yaş ve üzeri yaş grubunda ise düşüşe geçmektedir.

Çeşitlilik arayışı ile "eğitim durumuna" yönelik yapılan varyans analizi sonucu, "deneyim" arayışında "lisans" mezunu katılımcılar ile eğitim durumu daha yüksek/düşük katılımcılar arasında anlamlı farklılıklara rastlanılmış, "lisans" mezunu katılımcıların "deneyim" arayışına daha çok ilgi gösterdikleri tespit edilmiştir. Beldona ve diğ. (2010: 438) de benzer şekilde, yiyeceklerde çeşitlilik ve deneyim arayışında olan tüketiciler ile eğitimleri arasında anlamlı farklılıklar tespit etmişlerdir.

Yapılan çalışma, Kapadokya'yı ziyaret eden yabancı turistler ile sınırlıdır. Çalışmada, örneklemin kolayda örnekleme yöntemi ile seçilmiş olması, sonuçlarının 
genellenebilirlik düzeyini düşürmektedir. Ancak, yiyecek üretim tesisleri, şarap tadım merkezleri, festivalleri, pazarları gibi turizmi destekleyici ürünleri ile Kapadokya bölgesi gastronomi turizmi kapsamında turistlerin ilgisini çekmekte, bölgenin kültürel değerlerini görmek amaçlı ziyaretlerde bulunan turistlerin de sözü geçen turizm arzlarından ek deneyimler edindikleri görülmektedir.

Analizlerde ortaya konulan bulgular yabancı katılımcılara yöneliktir. Yerli turistler kapsam dışı tutulmaktadır. Yerli turistlerin yiyeceklere yönelik çeşitlilik arayışlarının ortaya konup karşılaştırılabilmesi amacıyla, gelecekte yerli turistlere yönelik de çalışmalar yapılması önerilebilir.

\section{Kaynakça}

Akdağ, G., Akgündüz, Y., Güler, O., ve Benli, S. (2015). Bir seyahat motivasyon aracı olarak gastronomi: Hatay'ı ziyaret eden yerli turistlerin seyahat motivasyonları, yiyecek-içecek deneyimleri ve seyahat memnuniyetleri üzerine bir çalışma. I. Avrasya Uluslararası Turizm Kongresinde sunulan bildiri. Selçuk Üniversitesi, Konya.

Alpar, R. (2011). Uygulamalı çok değişkenli istatistiksel yöntemler. Ankara: Detay Yayıncılık.

Au, N. ve Law, R. (2002). Categorical classifaction of tourism dining. Annals of Tourism Research. 29 (3). 819-833.

Baltas, G.,Kokkinaki, F., ve Loukopoulou, A. (2011). Does variety-seeking at the attribute level vary between utilitarian and hedonic products? An experimental study. Proceedings of the 2011 Academy of Marketing Conference. Liverpool, England, University of Liverpool.

Baumgartner, H., ve Steenkamp, J. B. E. M. (1996). Exploratory consumer buying behavior: Conceptualization and measurement. Journal of Research in Marketing, 13(2), 121-137.

Bayrakçı, S. (2014). Yerel yemek tüketim motivasyonlarının turistlerin tekrar ziyaret niyetlerine etkisi: Gaziantep'i ziyaret eden yerli turistler üzerine bir araştırma. Yayımlanmamış yüksek lisans tezi, Mersin Üniversitesi, Mersin.

Bekar, A., ve Kılıç, B. (2014) Turistlerin gelir düzeylerine göre destinasyondaki gastronomi turizmi etkinliklerine katılımları. Uluslararası Sosyal ve Ekonomik Bilimler Dergisi, 4(1), 19-26.

Beldona, S.,Moreo, A. P., ve DasMundhra, G. (2010). The role of involvement and variety-seeking in eating out behaviors. International Journal of Contemporary Hospitality Management, 22(3), 433-444.

Berne, C.,Mugica, J. M., ve Yagüe, M. J. (2001). The effect of variety-seeking on customer retention in services. Journal of Retailingand Consumer Services, 8(6), 335-345.

Boyne, S., Williams, F., ve Hall, D. (2002). On the trail of regional success: Tourism, food production and the Isle of Arran Taste Trail. Hjalager, A.M. ve Richards, G. (Eds.), Tourism and Gastronomy içinde (s. 91-114). London: Loutledge.

Chang, R. C.,Kivela, J., ve Mak, A. H. (2011). Attributes that influence the evaluation of travel dining experience: When East meets West. Tourism Management, 32(2), 307-316.

Cohen, E., ve Avieli, N. (2004). Food in toursim. Attraction and impediment. Annals of Tourism Research, 31(4), 755-778.

Çağlı, I. B. (2012). Türkiye'de yerel kültürün turizm odaklı kalkınmadaki rolü: Gastronomi turizmi örneği. Yayımlanmamış yüksek lisans tezi, İstanbul Teknik Üniversitesi, İstanbul. 
Desai, K. K., ve Trivedi, M. (2014). Do consumer perceptions matter in measuring choice variety and variety seeking? Journal of Business Research, 67(1), 27862792.

Enright, M. J., ve Newton, J. (2005). Determinants of tourism destination competitiveness in Asia Pacific: Comprehensiveness and universality. Journal of Travel Research, 43(4), 339-350.

Enrique Bigne, J.,Sanchez, I., ve Andreu, L. (2009). The role of variety seeking in short and long run revisit intentions in holiday destinations. International Journal of Culture, Tourism and Hospitality Research, 3(2), 103-115.

Fotopoulos, C., Krystallis, A., Vassallo, M., ve Pagiaslis, A. (2009). Food Choice Questionnaire (FCQ) revisited. Suggestions for the development of an enhanced general food motivation model. Appetite, 52(1), 199-208.

Frochot, I. (2003). An analysis of regional positioning and its associated food images in French tourism regional brochures. Journal of Travel and Tourism Marketing, 14(3-4), 77-96.

Germann, M. J. (2004). Tasting an imagined Thailand: Authenticity and culinary tourism in Thai restaurants. . L. M. Long (Eds.), Culinary Tourism içinde (ss. 5357), Lexington: University Press of Kentucky.

Guzman, T. L. ve Canizares, S. S. (2011). Gastronomy, tourism and destination differentiation: A case study in Spain. Review of Economics\& Finance. 2 (1). 6372.

Ha, J., ve Jang, S. S. (2013). Variety seeking in restaurant choice and its drivers. International Journal of Hospitality Management,32, 155-168.

Hall, C. M., ve Sharples, L. (2003).The consumption of experiences or the experience of consumption? An introduction to the tourism of taste.Hall, C. M., Sharples, L., Mitchell, R., Macionis, N., ve Cambourne, B. (Eds.). Food Tourism Around The World içinde (ss. 1-24). London: Butterworth Heinemann.

Handszuh, H. F. (2000). Local food in tourism policies.WTO-CTO Local Food and Tourism International Conference, Larnaka, Cyprus.

Hjalager, A. M., ve Corigliano, M. A. (2000). Food for tourists- -determinants of an image. International Journal of Tourism Research, 2(4), 281-293.

Hu, B. A., Morrison, A. M. ve O'Leary, J. T. (2002).An analysis of the variety-seeking behavior of the U.S. visiting friends and relatives market. The Journal of Tourism Studies, 13(2), 28-40.

Ignatov, E., ve Smith, S. (2006). Segmenting Canadian culinary tourists. Current Issues in Tourism, 9(3), 235-255.

Inman, J. J. (2001). The role of sensory-specificsatiety in attribute-level variety seeking. Journal of Consumer research, 28(1), 105-120.

Jang, S. S., ve Feng, R. (2007). Temporal destination revisit intention: The effects of novelty seeking and satisfaction. Tourism Management, 28(2), 580-590.

Joliffe, L. (2003). The lure of tea: History, traditions and attractions. Hall, C. M.,Sharples, L., Mitchell, R., Macionis, N., ve Cambourne, B. (Eds.). Food Tourism Around the World içinde (ss. 121-136). Burlington: ButterworthHeinemann.

Jung, H. S., ve Yoon, H. H. (2012). Why do satisfied customers switch? Focus on the restaurant patron variety-seeking orientation and purchase decision involvement. International Journal of Hospitality Management, 31(3), 875-884.

Kahn, B. E. (1995). Consumer variety-seeking among goods and services: An integrative

review. Journal of Retailingand Consumer Services, 2(3), 139-148.

Kalaycı, Ş. (2009). SPSS uygulamalı çok değişkenli istatistik teknikler.Ankara: Asil Yayın Dağıtım. 
Kesici, M. (2012). Kırsal turizme olan talepte yöresel yiyecek ve içecek kültürünün rolü. KMÜ Sosyal ve Ekonomik Araştırmalar Dergisi, 14(23), 33-37.

Kim, Y. G., Eves, A., ve Scarles, C. (2009). Building a model of local food consumption on trips and holidays: A grounded theory approach. International Journal of Hospitality Management, 28, 423-431.

Kim, Y. H.,Goh, B. K., ve Yuan, J. (2010). Development of a multi-dimensional scale for measuring food tourist motivations. Journal of Quality Assurance in Hospitality and Tourism, 11(1), 56-71.

Kivela, J., ve Crotts, J. C. (2006). Tourism and Gastronomy: Gastronomy's influence on how tourist experience a destinastion. Journal of Hospitality and Tourism Research, 30(3), 354-377.

Kivela, J., ve Crotts, J. C. (2009). Understanding travelers' experiences of gastronomy through etymology and narration. Journal of Hospitality and Tourism Research, 33(2), 161-192.

Kodaş, D. (2013). Yerli ziyaretçilerin yerel yiyecek tüketim güdülerinin belirlenmesi: Beypazarı Örneği. Yayımlanmamış yüksek lisans tezi, Anadolu Üniversitesi, Eskişehir.

Kwun, J. W., ve Oh, H. (2004). Effects of brand, price, and risk on customers' value perceptions and behavioral intentions in the restaurant industry. Journal of Hospitality and Leisure Marketing, 11(1), 31-49.

Kwun, D. J. W., Hwang, J. H., ve Kim, T. H. (2013). Eating-out motivations and varietyseeking behavior: An exploratory approach on loyalty behavior. Journal of Hospitality Marketing and Management, 22(3), 289-312.

Legoherel, P. (1998). Toward a market segmentation of the tourism trade: Expenditure levels and consumer behavior instability. Journal of travel and tourism marketing, 7(3), 19-39.

Legoherel, P., Dauce, B., ve Hsu, C. H. (2012). Divergence in variety seeking: An exploratory study among international travelers in Asia. Journal of Global Marketing, 25(4), 213-225.

Mak, A. H.,Lumbers, M., Eves, A., ve Chang, R. C. (2012). Factors influencing tourist food consumption. International Journal of Hospitality Management, 31(3), 928936.

McAlister, L., ve Pessemier, E. (1982). Variety seeking behavior: An interdisciplinary review. Journal of Consumer Research, 9(3), 311-322.

Meixner, O., ve Knoll, V. (2012). An expanded model of variety-seeking behaviour in food product choices. British FoodJournal,114(11), 1571-1586.

Menon, S., ve Kahn, B. E. (1995). The impact of context on variety seeking in product choices. Journal of Consumer Research, 22(3), 285-295.

Nakip, M. (2006). Pazarlama araştırmaları teknikler ve (SPSS destekli) uygulamalar. Ankara: Seçkin Yayıncılık.

Nicolau, J. L. (2010). Variety-seeking and inertial behaviour: The disutility of distance. Tourism Economics, 16(1), 251-264.

Pearson, D., Henryks, J., Trott, A., Jones, P., Parker, G., Dumaresq, D., ve Dyball, R. (2011). Local food: Understanding consumer motivations in innovative retail formats. British Food Journal, 113(7), 886-899.

Punj, G. (2011). Impulse buying and variety seeking: Similarities and differences. Journal of Business Research, 64(7), 745-748.

Quan, S., ve Wang, N. (2004). Towards a structual model of tourist experience: An illustration from food experiences in tourism. Tourism and Management,25, 297-305.

Ratner, R. K., Kahn, B. E., ve Kahneman, D. (1999). Choosing less-preferred experiences for the sake of variety. Journal of Consumer Research, 26(1), 1-15. 
Redl, S. (2013). Culinary tourism for young adult travellers and its connection to destination management. Unpublished bachelor thesis, Modul Vienna University.

Rızaoğlu, B., Ayazlar, R. A. ve Gençer, K. (2014). Yiyecek deneyimiyle ilgili bireysel eğilimlerin sosyo-demografik özellikler açısından değerlendirilmesi: Kuşadası'ına gelen yabancı turistler örneği. 14. Ulusal Turizm Kongresinde sunulan bildiri. Erciyes Üniversitesi, Kayseri.

Rimmington, M., ve Yüksel, A. (1998). Tourist satisfaction and food service experience: Results and implications of an empirical investigastion. Anatolia: An International Journal of Tourism and Hospitality Research, 9(1), 37-57.

Roehm, H. A., ve Roehm, M. L. (2005). Revisiting the effect of positive mood on variety seeking. Journal of Consumer Research, 32(2), 330-336.

Sanchez-Garcia, I.,Pieters, R., Zeelenberg, M., ve Bigne, E. (2012). When satisfied consumers do not return: Variety seeking's effect on short-and long-termintentions. Psychologyand Marketing, 29(1), 15-24.

Shenoy, S. S. (2005). Food tourism and the culinary tourist. Unpublished master thesis. A Thesis Presented to Graduate School of Clemson University.

Sims, R. (2009). Food, place and authenticity: Local food and the sustainable tourism experience. Journal of Sustainable Tourism, 17(3), 321-336.

Smith, S., ve Costello, C. (2009). Segmenting visitors to a culinary event: Motivations, travel behavior, and expenditures. Journal of Hospitality Marketing and Management, 18(1), 44-67.

Steenkamp, J. B. E., ve Baumgartner, H. (1992). The role of optimum stimulation level in exploratory consumer behavior. Journal of Consumer Research, 19(3), 434448.

Üner, M. M., Güçer, E., ve Taşçı, A. (2006). Türkiye turizminde yükselen destinasyon olarak İstanbul şehrinin imajı. Anatolia: Turizm Araştırmaları Dergisi,17(2), 189201.

Van Trijp, H. C., ve Steenkamp, J. B. E. (1992). Consumers' variety seeking tendency with respect to foods: Measurement and managerial implications. European Review of Agricultural Economics, 19(2), 181-195.

Van Trijp, H. C.,Hoyer, W. D., ve Inman, J. J. (1996). Why switch? Product category: level explanations for true variety-seeking behavior. Journal of Marketing Research, 33(3), 281-292.

Winter, T.,Teo, P., ve Chang, T. C. (2008). Asia on tour: Exploringthe Rise of Asian Tourism. Oxon: Routledge.

Yüksel, A. (2001). Managing customer satisfaction and retention: A case of tourist destinations, Turkey. Journal of Vacation Marketing, 7(2), 153-168. 